\title{
Ekstrapulmoner malignitelere bağlı endobronşiyal metastazlar
}

\author{
Efsun Gonca UĞUR \\ CHOUSEIN ${ }^{1}$ \\ Mehmet Akif ÖZGÜL ${ }^{1}$
}

1 İstanbul Yedikule Göğüs Hastalıkları ve Göğüs Cerrahisi Eğitim ve Araştırma Hastanesi, Göğüs Hastalıkları Kliniği, İstanbul, Türkiye

${ }^{1}$ Clinic of Chest Diseases, Yedikule Chest Diseases and Chest Surgery Training and Research Hospital, Istanbul, Turkey
Makale atıfi: Uğur Chousein EG, Özgül MA. Ekstrapulmoner malignitelere bağlı endobronşiyal metastazlar. Tuberk Toraks 2019;67(3):219-24.

Yazışma Adresi (Address for Correspondence)

\section{Dr. Efsun Gonca UĞUR CHOSEIN}

İstanbul Yedikule Göğüs Hastalıkları ve Göğüs Cerrahisi Eğitim ve Araştırma Hastanesi,

Göğüs Hastalıkları Kliniği,

ISTANBUL - TÜRKIYE

e-mail: efsungoncachousein@yahoo.com

\section{ÖZ}

\section{Ekstrapulmoner malignitelere bağlı endobronşiyal metastazları}

Ekstrapulmoner malignitelere bağlı akciğer metastazlarının parankimal, plevral ve mediastinal lenf nodu tutulumlarına sıklıkla rastlanırken, endobronşiyal olarak saptanmaları nadir rastlanan bir durumdur. Girişimsel pulmonolojide değerlendirilerek tanı konulan ve tedavi edilen santral hava yolu obstrüksiyonlarının bir kısmı endobronşiyal metastazlardır. Girişimsel işlemlerle endobronşiyal metastazlara (EBM) kimi zaman erken tanı konularak, kimi zaman da ilerlemiş malignitesi ve solunumsal semptomu olan olguların semptomlarında hızlı palyasyon sağlanabilir.

Anahtar kelimeler: Girişimsel pulmonoloji; endobronşiyal metastaz; ekstrapulmoner malignite

\section{ABSTRACT}

Endobronchial metastases secondary to extrapulmonary malignancies

Although parenchymal, pleural and mediastinal lymph node locations of metastatic Lung cancer are frequently seen, they are rarely found endobronchially. Endobronchial metastases comprise a portion of central airway obstructions that are diagnosed and treated by interventional pulmonology. Interventional procedures for endobronchial metastases (EBM) can help us reach early diagnosis, or in advanced cases with respiratory symptoms, used palliatively.

Key words: Interventional pulmonology; endobronchial metastases; extrapulmonary malignancy

OTelif Hakkı 2019 Tüberküloz ve Toraks. Makale metnine

www.tuberktoraks.org web adresinden ulaşılabilir. 


\section{TANIM}

Histolojik olarak ekstrapulmoner bir malignite ile ilişkili olduğu kanıtlanmış, bronkoskopik olarak saptanabilen, trakea ve bronşların bir bölümünde yer alan malign lezyonlara endobronşiyal metastaz (EBM) denir ve bu terim tarihte ilk kez 1890 'da Zenker tarafından tanımlanmıştır $(1,2)$.

Uzak yerleşimli bir tümörün nasıl olup da akciğerlere metastaz yaptığına dair teorilere baktığımız zaman, lenfatik ve hematojen dolaşımla primer tümörün mukozal lenfatikler ile bronş epiteline ulaştığı, burada ülserasyona yol açarak lümen içerisine doğru büyüdüğü tezlerine rastlarız $(3,4)$.

Kiryu ve arkadaşları EBM'lerin oluşum paternlerini dört sınıfa ayırmışlardır (Şekil 1) (1):

Tip 1: Bronşa direkt metastaz,

Tip 2: Parankimal lezyonun bronşa invazyonu,

Tip 3: Mediastinal ya da hiler lenf nodlarının bronşa invazyonu,

Tip 4: Periferik lezyonun proksimal bronş boyunca büyümesi.

\section{EPIDEMIYOLOJi}

Dünya Sağlık Örgütü (DSÖ)'ne bağlı “International Agency for Research on Cancer (IARC)" In verilerine göre; 2018 yılında dünyada 18 milyondan fazla yeni tümör tanısı konulmuş olup, sıklık sırasına göre primer akciğer tümörleri, kolon, meme ve prostat kanseri başta gelmektedir.

Tüm malignitelerin 1/3'ünden fazlasının seyirleri esnasında, akciğer parankimi, plevra ve mediasten lenf nodlarına metastaz yapmaları oldukça sık rastlanan bir durumdur. Ancak malignitelerin, özellikle de ekstrapulmoner olanların endobronşiyal metastazları oldukça nadir rastlanan bir durumdur $(3,5)$.

Literatüre baktığımız zaman endobronşiyal metastaz sıklığı ile ilgili verilen rakamlar genelde ekstratorasik solid tümörlere aittir. Ancak biz burada EBM'lerin orijinlerini ekstratorasik değil, ekstrapulmoner olarak gözden geçirmeyi planlayarak, intratorasik ve ekstra-

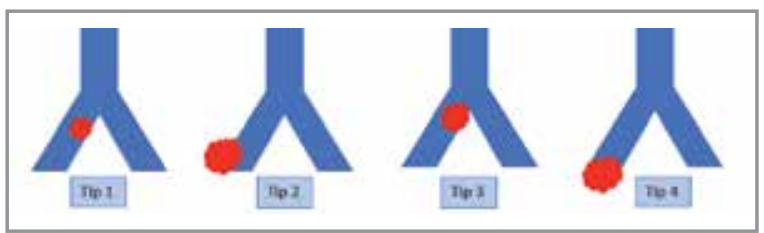

Şekil 1. Kriyu ve arkadaşlarının EBM oluşum patern sınıflaması. torasik tüm maligniteleri değerlendirmek istedik (Şekil 2).

Oshikawa ve arkadaşlarının serisinde; akciğere metastaz yapan ekstrapulmoner malignitelerin ancak $\% 23$ 'ünün endobronşiyal metastaz olarak ortaya çıktığı belirtilmiş̧tir (6).

Braman ve Whitcomb ise, bronkoskopik olarak ulaşılabilen santral hava yollarında saptanabilen ekstrapulmoner kaynaklı EBM prevalansını \%2 olarak belirtmişlerdir (7).

Akciğere komşu organlar olan larinks, tiroid, özefagus, timus gibi organlara ait endobronşiyal metastazlara rastlanabileceği gibi, meme, over, prostat, kolon, rektum, melanom, seminom, sarkom, schwannom, plazmositom, adrenal bez, penis, vajina, safra kesesi ve parotis bezi gibi uzak organlara ait endobronşiyal metastazlara da rastlanabilmektedir $(5,8,9)$.

Endobronşiyal metastazlar; olguların primer tümörlerinin seyri esnasında özellikle de ilerlemiş dönemlerinde saptanabilecekleri gibi, ilk tanı alan malignite de olabilirler (5).

Endobronşiyal olarak saptanan tüm malignitelerin sadece \%1.1'i metastatiktir $(10,11)$.

Endobronşiyal metastazlara en sık yol açan primer malignite sıklık sırasına göre 2000'li yıllardan önce meme, kolorektal, renal ve serviks kanseri iken, 2000 'li yıllardan sonra kolorektal, meme, renal, uterus kanseridir. Bu sıralamadaki değişimin nedeni uluslararası artan kolorektal karsinom insidansı ve farklı etnik kökenlerdir (12).

Endobronşiyal sistem, trakea ve sağ-sol bronşiyal sistemler olarak ele alındığında ise; trakeaya en sık metastaz yapan malignitenin başta iyi diferansiye tiroid kanserleri olmak üzere sırasıyla özefagus, kolon kanserleri, renal hücreli karsinom, melanom, meme kanserleri olduğu bildirilmiştir (11).

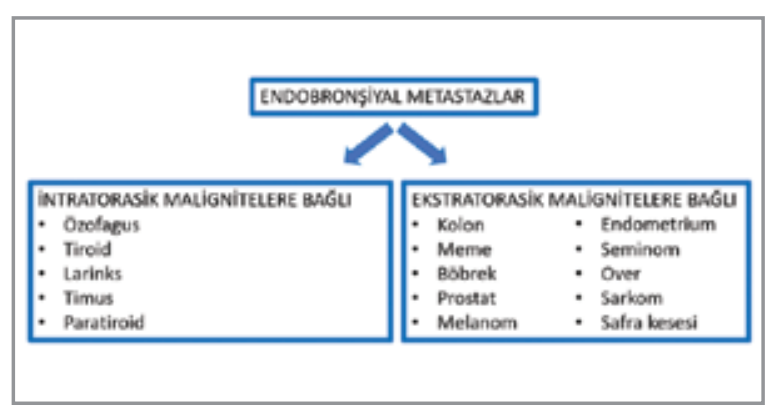

Şekil 2. Endobronşiyal metastazlar. 
Endobronşiyal metastazı olan olguların primer tümör tanılarından sonra endobronşiyal metastaz tanısı almalarına kadar geçen ortalama süre 32.8-63.5 ay, ortalama sağkalımları ise 7-18 ay olarak saptanmıştır (12).

Bu kısa sağkalım süresine rağmen, EBM'ler her zaman umut karartıcı durumlar olmayıp, kimi zaman cerrahi uygulanabilen olgulardır (13).

\section{TANI}

\section{Klinik Bulgular}

EBM'si olan hasta prototipi, ekstrapulmoner malignite tanılı, yaş ortalaması 53 olan kadın hastadır (12).

Sadece rutin taramaları sırasında radyolojik patoloji saptanan asemptomatik hastalar olabilir, bu nedenle bilinen bir malignite varlığında hastaların basit gibi görünen semptomları bile daha dikkatli irdelenmelidir. Endobronşiyal metastazlar genelde primer tümörlerin ilerlemiş safhalarında ortaya çıktıklarından, hastaların primer tümörlerine bağlı klinikleri de solunumsal semptomlarına eşlik edebilir (12).

En sık rastlanan solunumsal semptomlar, öksürük (\%80), nefes darlığı (\%61) ve hemoptizidir (\%61) $(12,14)$.

\section{Görüntüleme Yöntemleri}

Akciğer grafisi normal olabileceği gibi, tümöre bağlı kitlesel opasite, atelektazi, plevral sıvı, multipl parankimal nodüller, mediastinal genişleme gibi bulgular izlenebilir. En sık rastlanan radyolojik bulgu; eşlik eden postobstrüktif pnömoni olsun olmasın atelektazidir.

Toraks bilgisayarlı tomografi (BT)'de trakea, sağ ve sol ana bronş içinde lümen içindeki lezyona ait yumuşak doku dansitesi izlenebilir $(9,12,14,15)$.

İki ya da üç boyutlu toraks BT'ler, PET-BT, sanal bronkoskopik görüntüler, toraks manyetik rezonans (MR) görüntüleme de tanı aşamasında yardımcı olan diğer görüntüleme yöntemleridir. Fizyolojik değerlendirmede solunum fonksiyon testleri normal olabileceği gibi, akım- volüm eğrisinde büyük hava yolu obstrüksiyonu gösteren düzleşme izlenebilir (Şekil 3) (17).

\section{Bronkoskopik Değerlendirme (Rijid/Fiberoptik)}

Bronkoskopik bulgular; primer tümöre bağlı karakteristik bir yapıda olabileceği gibi primer akciğer tümörlerinden çoğu zaman görünüm olarak ayırt

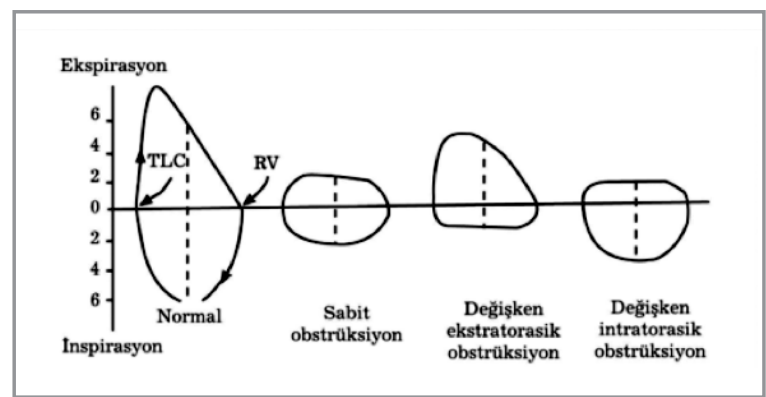

Şekil 3. Solunum fonksiyon testi- akım-volüm eğrisi.

edilemezler. Sıklıkla bronş içinde üzeri nekrozla kaplı nodüler görünüm, etrafı düzensiz submukozal yayılım, dış bası ya da bronş çapında daralmaya rastlanabilir (Resim 1-3) (16,18,19).

Nedeni bilinmemekle birlikte, daha önce yayınlanmış serilerde endobronşiyal metastazların sıklıkla sağ bronşiyal istemi tercih ettikleri dikkati çekmektedir $(1,12)$.

Renal kanser ve tiroid kanserlerine bağlı EBM'ler diğer kanserlere göre bronkoskopik işlem esnasında ciddi kanama gelişmesine daha yatkındırlar (20).
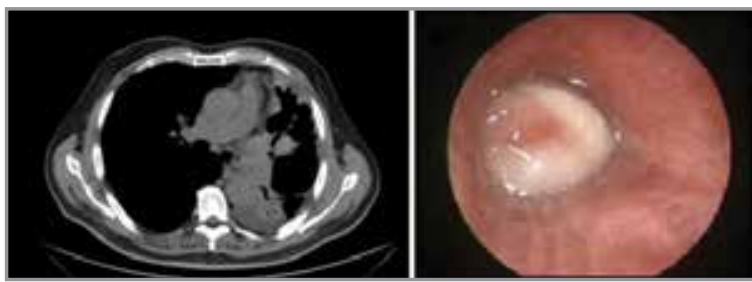

Resim 1. Renal karsinom; sol ana bronşta \%100 obliterasyona yol açan endobronşiyal lezyon.

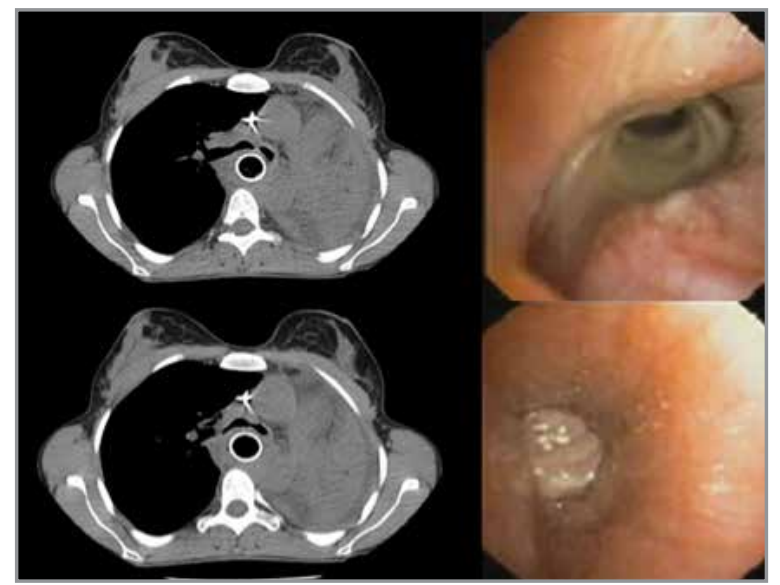

Resim 2. Özefagus karsinomu, sağ ana bronşta posterior duvarda dıştan bası ve intermedier bronşta endobronşiyal lezyon. 


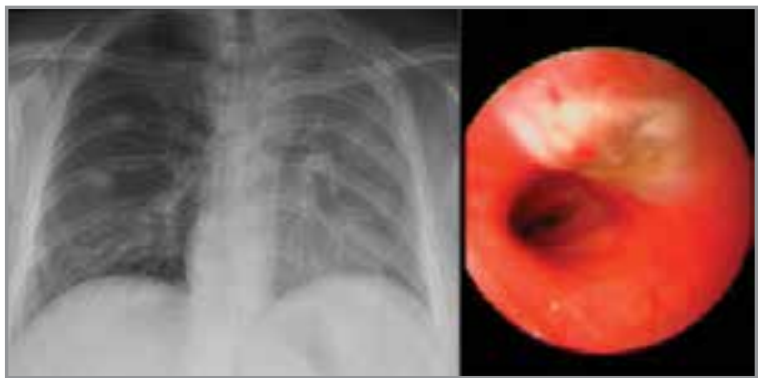

Resim 3. Rektum karsinomu; sol üst lobu $\% 100$ oblitere eden endobronşiyal lezyon.

\section{Patoloji}

Akciğerlerin herhangi bir bölümüne ekstrapulmoner bir malignitenin metastaz yapma olasılığı oldukça yüksek iken, endobronşiyal alana metastaz yapmaları oldukça nadir bir durumdur. Üstelik hem makroskobik hem de mikroskobik olarak primer akciğer tümörlerinden ayırt edilmeleri de çok güçtür $(12,21)$.

Ekstrapulmoner tümörlere bağlı metastazların tanısının netleşmesi için histolojik analizler ile tanı konfirme edilmeli ve primer tümör ile patolojik kıyaslama yapılmalıdır. Rosenblatt ve arkadaşları, erken evrelerde bir endobronşiyal lezyonun bozulmamış bir epitel tabaka ve subepitelyal lenfatikler ile kaplı tümöral kitleden oluştuğunu göstermişlerdir. Östrojen/progesteron reseptör durumu, HPV-DNA analizi, CK7, CK20, tiroid transkripsiyon faktör-1 ve apoprotein-A1 gibi ek moleküler biyolojik çalışmalar primer ve metastatik tümörün birbirinden ayırt edilmesini sağlayacaktır (12,22-24).

\section{TANI ve TEDAVIDE GIRIŞiMSEL BRONKOSKOPIK iŞLEMLER}

EBM'ler için seçilecek tedavi modalitesine; primer tümörün özellikleri, biyolojik davranışı, anatomik lokasyonu, ek malign odak varlığı, mevcut semptomlar, hastanın performansı ve hayat beklentisi değerlendirilerek karar verilmelidir (21-25).

Girişimsel bronkoskopik işlemler bazen ilk tanıda bazen de malignite tanılı hastaların ilerleyen dönemlerinde ortaya çıkan endobronşiyal metastazların hastada yarattığı semptomlarda hızlı bir şekilde palyasyon sağlar (Resim 4,5) (12).

Endobronşiyal metastazlı bir olguya yaklaşım, malign santral hava yolu obstrüksiyonlu olgulardakine benzer. illk amaç hava yolunun açıklığını sağlamaktır ki bu amaçla; mekanik ve termal yöntemler kullanılabilir.

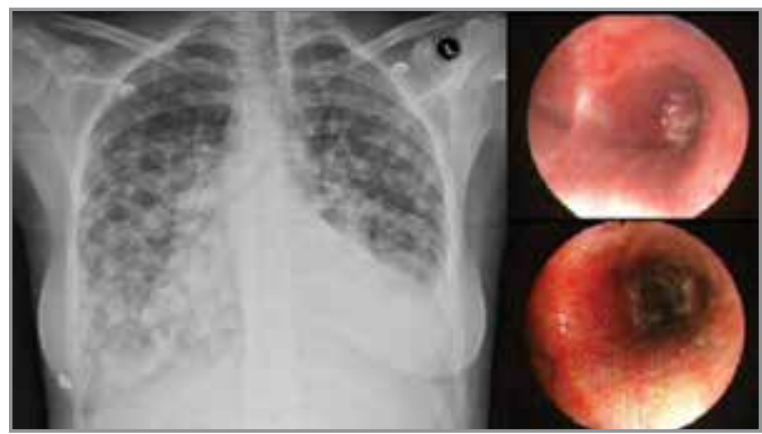

Resim 4. Over karsinomuna bağlı sağ ana bronşta endobronşiyal metastaz; endobronşiyal tedavi öncesi ve sonrası.

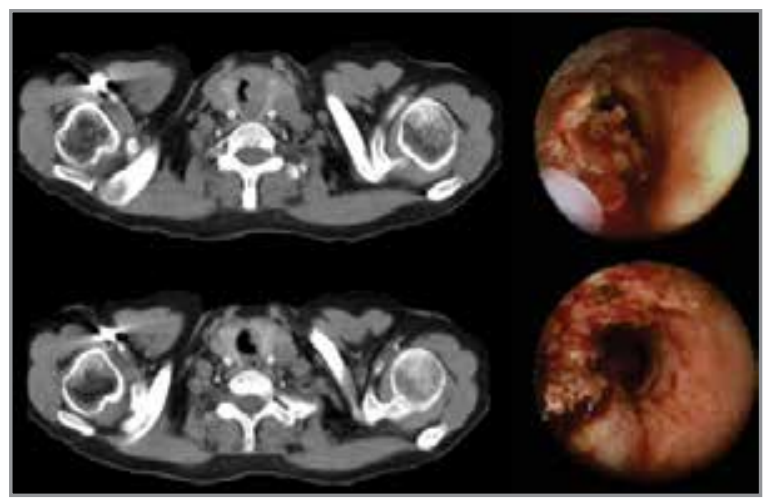

Resim 5. Larinks karsinomuna bağlı trakeada endobronşiyal metastaz; endobronşiyal tedavi öncesi ve sonrası.

1. Mekanik yöntemler: Rezeksiyon/dilatasyon (rijid tüpün kendisi, balon, buji ve kesi),

2. Termal yöntemler (kriyoterapi, argon plazma koagülasyon APC, laser, elektrokoter).

\section{Mekanik Yöntemler}

Mekanik rezeksiyon/dilatasyon: Rijid tüpün kendisi ile "çevir-it" tekniğiyle yapılan bu yöntem kısa sürede hızlı yanıt alınması, tekrarlanabilir olması nedeniyle hayat kurtarıcıdır. Tecrübeli ellerde yapılırsa da oldukça güvenli olan bir yöntemdir. Laserasyon, rüptür, pnömotoraks, pnömomediastinum, hemoraji gibi komplikasyonlar görülebilir $(26,27)$.

\section{Termal Yöntemler}

\section{Soğuk yöntemler:}

- Kriyoekstraksiyon ve kriyoterapi: Dokuyu dondurma yöntemi ile ortamdan uzaklaştırmak veya lokal uygulama ile dokuyu -40, -60 dereceye kadar soğutarak koagülasyon nekrozuna yol açarak yok eder. İçerisinde nitröz oksit, karbondioksit ve sıvı nitrojen ihtiva eder. Etkisi geç ortaya 
çıkar, işlem tekrar sıklığını azalttığına dair veriler mevcuttur.

\section{Sıcak yöntemler:}

- $\quad$ Argon plazma koagülasyon: Direkt temas gerektirmeyen, hızlı etki eden dokuya penetrasyonu sığ olduğu için düşük komplikasyon ve kanama riskine sahip bir termal tedavi yöntemidir.

- Elektrokoter: Dokuda koagülasyona yol açan termal tedavi yöntemidir. Ancak perforasyon riski yüksektir, tüm diğer termal tedavi yöntemlerindeki gibi kanama açısından güvenli bir yöntemdir.

- Laser: İşlem yapılan alanı koagüle ederek etki eden bu yöntem hızlı etkili olması, düşük kanama riski nedeniyle tercih edilebilecek yöntemlerdendir. Nd-YAG, CO2, Diot olmak üzere farklı tipleri vardır.

Hava yolu açıklığının korunması amacıyla kullanılan yöntem ise stentlemedir.

Hızlı etkili bir tedavi yöntemidir. Stentler metal, silikon, polifleks gibi çeşitli materyallerden üretilen cihazlardır. Stenozun uzunluğu, lokasyonu gibi noktalar dikkate alınarak düz ya da Y-stentler bu amaçla kullanılabilir (Resim 6) $(28,29)$.

\section{Multimodalite Tedavi}

Şu ana kadar bahsedilen endoskopik tedaviler tek başlarına elbette uygulanabilir. Ancak multimodalite tedavi dediğimiz, birden fazla tekniğin bir arada kullanıldığı durumlarda tedavi başarısının daha yüksek olduğu bilinmektedir (Resim 6) (30).

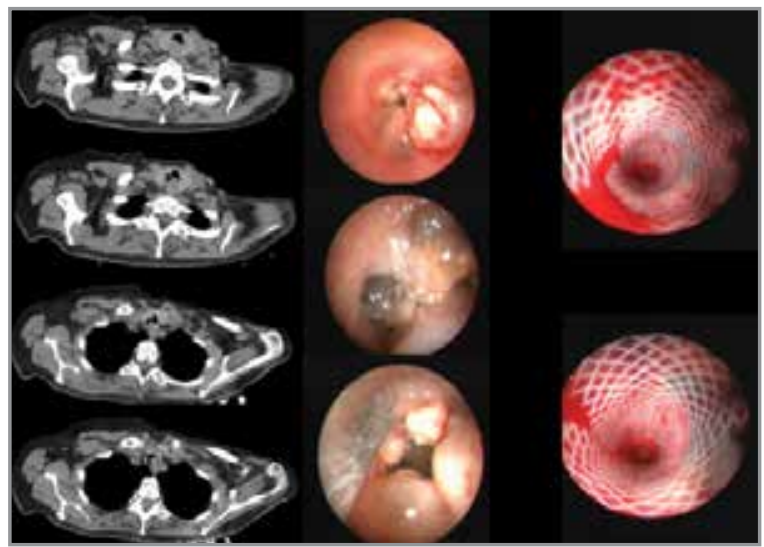

Resim 6. Malign melanoma bağ ${ }_{ı}$ endobronşiyal metastaz; endobronşiyal tedavi ve polifleks stent implantasyonu.

\section{SONUÇ}

Tüm malignitelerin takibinde, akciğerlerin metastaz açısından en olası organ olduğu göz önüne alınmalı, özellikle pulmoner semptomların varlığında hastalar daha ayrıntılı irdelenmelidir.

Girişimsel bronkoloji; pulmoner malignitelerde olduğu gibi, ekstrapulmoner malignitelere bağlı endobronşiyal metastaz varlığında kimi zaman erken tanıda, kimi zaman da ilerlemiş dönemlerde hastaların semptomlarının hızlı palyasyonunda ve sağkalımlarının uzamasında fonksiyonel bir göreve sahiptir.

\section{KAYNAKLAR}

1. Kiryu T, Hoshi H, Matsui E, Iwata H, Kokubo M, Shimokawa K, Kawaguchi S. Endotracheal/endobronchial metastases: clinicopathologic study with special reference to developmental modes. Chest 2001;119:768-75.

2. Zenker K. Zur Lehre von der metastasenbildung der sarcome. Virchows Arch Pathol Anat 1890;120:68.

3. Yokota J. Tumor progression and metastasis. Carcinogenesis 2000;21:497-503.

4. Rosenblatt MB, Lisa JR, Trinidad S. Pitfalls in the clinical and histologic diagnosis of bronchogenic carcinoma. Chest 1966;49:396-404.

5. Marchioni A, Lasagni A, Busca A, Cavazza A, Agostini $L$, Migaldi $M$, et al. Endobronchial metastasis: an epidemiologic and clinicopathologic study of 174 consecutive cases. Lung Cancer 2014;84:222-8.

6. Oshikawa K, Ohno S, Ishii Y, Kitamura S. Evaluation of bronchoscopic findings in patients with metastatic pulmonary tumor. Intern Med 1998;37:349-53.

7. Braman SS, Whitcomb ME. Endobronchial metastasis. Arch Intern Med 1975;135:543-7.

8. Compeau CG, Keshavjee S. Management of tracheal neoplasms. The Oncologist 1996;1:347-53.

9. Ikezoe J, Johkoh T, Takeuchi N, Ishida T, Morimoto S, Kitamura l, et al. CT findings of endobronchial metastasis. Acta Radiologica 1991;32:455-60.

10. Kreisman $H$, Wolkove $N$, Finkelstein $H S$, Cohen C, Margolese $R$, Frank H. Breast cancer and thoracic metastases: review of 119 patients. Thorax 1983;38:1759 .

11. Madariaga ML, Gaissert HA. Secondary tracheal tumors: a systematic review. Ann Cardiothorac Surg 2018;7:183-96.

12. Kim $J H$, Min D, Song $S H$, Lee $J H$, Jeong HC, Kim EK Endobronchial metastases from extrathoracic malignancies: recent 10 years' experience in a single University Hospital. Tuberc Respir Dis 2013;74:169-76.

13. Shepherd MP. Endobronchial metastatic disease. Thorax 1982;37:362-5 
14. Sorensen JB. Endobronchial metastases from extrapulmonary solid tumors. Acta Oncologica 2004;43:73-9.

15. Debnath J, George RA, Satija L, Ahmed S, Rai SP, Roy S. Virtual bronchoscopy in the era of multi-detector computed tomography: Is there any reality? Med I Armed Forces India 2013; 69:305-10.

16. Dogan C, Sagmen SB, Parmaksız ET, Fidan A, Kıral $N$, Salepçi B, et al. Features of endobronchial metastases from extrathoracic malignancy and positron emission tomography-computerized tomography findings. Eurasian J Pulmonol 2018;20:37-42.

17. Ranu $H$, Wilde $M$, Madden B. Pulmonary function tests. Ulster Med I 2011;80:84-90.

18. Oshikawa K, Ohno S, Ishii Y, Kitamura S. Evaluation of bronchoscopic findings in patients with metastatic pulmonary tumor. Intern Med 1998;37:349-53.

19. Ku GY, Goodman KA, Rusch VW, Ilson DH. Successful treatment of esophageal cancer with airway invasion with induction chemotherapy and concurrent chemoradiotherapy. J Thorac Oncol 2009;4:432-34.

20. Bernasconi $M$, Koegelenberg CFN, Koutsokera A, Ogna $A$, Casutt $A$, Nicod $L$, et al. latrogenic bleeding during flexible bronchoscopy: risk factors, prophylactic measures and management. ERJ Open Res 2017;3:00084-2016

21. Akoglu S, Uçan ES, Celik G, Sener G, Sevinç C, Kilinç O, Itil O. Endobronchial metastases from extrathoracic malignancies. Clin Exp Metastasis 2005;22:587-91.

22. Rosenblatt MB, Lisa JR, Collier F. Criteria for the histologic diagnosis of bronchogenic carcinoma. Dis Chest 1967;51:587-95.
23. Kummar S, Fogarasi M, Canova A, Mota A, Ciesielski T. Cytokeratin 7 and 20 Staining for the diagnosis of lung and colorectal adenocarcinoma. Br J Cancer 2002;86:1884-7.

24. Wilson RW, Moran CA. Primary melanoma of the lung: a clinicopathologic and immunohistochemical study of eight cases. Am J Surg Pathol 1997;21:1196-202.

25. Guibert N, Mhanna L, Droneau S, Plat G, Didier A, Mazieres J, et al. Techniques of endoscopic airway tumor treatment. J Thorac Dis 2016;8:3343-60.

26. Sachdeva A, Pickering EM, Lee HJ. From electrocautery, balloon dilatation, neodymiumdoped:yttrium-aluminumgarnet (Nd:YAG) laser to argon plasma coagulation and cryotherapy. I Thorac Dis 2015;7:363-79.

27. Mitchell PD, Kennedy MP. Bronchoscopic management of malignant airway obstruction. Adv Ther 2014;31:512-38.

28. Miwa K, Matsuo T, Takamori S, Sueyoshi S, Mitsuoka M, Fujita $H$, et al. Temporary stenting for malignant tracheal stenosis due to esophageal cancer: a case report. Jpn J Clin Oncol 2002;32:27-9.

29. Nakamura $T$, Tajima $T$, Ogimi $T$, Miyakita $H$, Nitta $M$, Myojin K, et al. Expandable metallic stent for endobronchial metastasis from colorectal cancer: reports of 2 cases. Tokai J Clin Med 2017;20:79-84.

30. Bolliger CT. Multimodality treatment of advanced pulmonary malignancies. Interventional bronchoscopy. Prog Respir Res 2000;30:187-96. 